\title{
Further use of deoxyribonuclease in a screening test for Serratia
}

\author{
HARRY R. ELSTON AND JAMES H. ELSTON \\ From the Microbiology Research Laboratory, \\ Veterans Administration Hospital, Omaha, Nebraska, U.S.A.
}

SYNOPSIS The deoxyribonuclease (DNase) test is useful in classifying Serratia bacilli and in differentiating it from the Hafnia group, E. cloacae, and E. liquefaciens. It is recommended as a differential test in enteric bacteriology because of its specificity, the convenience of its use, and the rapidity with which it can be performed.

Although the deoxyribonuclease (DNase) test has been used primarily as a test to determine potentially pathogenic staphylococci (Elston and Fitch, 1964; Fusillo and Weiss, 1959; Weckman and Catlin, 1957) it shows potential as a diagnostic tool in identifying Serratia species. This is particularly true of nonpigmented strains. Production of DNase has been associated mainly with pathogenic cocci (Brown, 1950; Cunningham, 1959; Fusillo and Weiss, 1959; Potter and Laskowski, 1959; Wannamaker, 1958; Weckman and Catlin, 1957) but a wide variety of microorganisms has been found to produce this enzyme. These have included Bacillus subtilis, Clostridium septicum, Corynebacterium, Pasteurella pestis, Pseudomonas, Achromobacter, Escherchia coli, and Serratia marcescens. In recent years, DNase production in Enterobacteriaceae has been investigated in greater detail (Lehman and Richardson, 1964; Rothberg and Swartz, 1965; Valu, 1966).

From time to time reports have appeared in the literature of the isolation of Serratia from such clinical sources as abscesses, blood, sputa, urine, and wounds. Many of the Serratia strains recovered today are without pigmentation (pigments) and are late or nonlactose fermenters making cultural differentiation from some of the other enterobacteria difficult. Serratia are closely allied in their physiological behaviour with Hafnia species (Paracolobactrum aerogenoides) and some members of the Enterobacter (Aerobacter) group which may make a long series of biochemical procedures necessary to identify these organisms. A short set of routine tests, which includes DNase as a major differentiating factor, would be especially useful as a screening

Received for publication 3 July 1967. procedure in characterizing Serratia in a short period of time.

The present work was undertaken to explore further this potential.

\section{MATERIALS AND METHODS}

Ninety-three different strains (isolates) were used. These strains consisted of 51 determined species of Serratia, 33 determined species of Hafnia, six Enterobacter cloacae, and three Enterobacter liquefaciens organisms. Eighty-seven strains were fresh isolates obtained by the authors, while four were received from other laboratories, and one $E$. cloacae, and one $E$. liquefaciens strain were from the American Type Culture Company.

Routinely, Gram-negative bacilli isolated in our laboratory are subjected to six routine tests which form a basic combination helpful in determining other biochemical tests to be used in further identification of these organisms. These tests included: Kligler iron agar (Difco) used to determine the production of hydrogen sulphide, and the fermentation reaction on the slant (lactose) and in the butt (glucose) of the tube; Christensen's nutrient urea agar was selected as the test for the production of urease; a $1 \%$ Bacto tryptone broth was used in the test for indole with Kovac's reagent; growth on Simmons citrate agar was determined after inoculating with a straight wire by stabbing the butt and streaking the slant; gelatin liquefaction was investigated by growing the organisms in nutrient gelatin (Baltimore Biological Laboratory) at room temperature and at $37^{\circ} \mathrm{C}$; motility was demonstrated by a simple wet mount preparation, ringed with vaseline, from the tryptone broth culture after six to 18 hours' growth. When the latter method produced negative results, two tubes of motility medium (Difco) were inoculated. Tubes were incubated at room temperature and at $37^{\circ} \mathrm{C}$. The DNase test was added 
to this regimen when growth on Kligler iron agar produced an acid reaction only in the butt, when gelatin was liquefied, and when the organism was motile. A $1 \%$ lactose solution in peptone broth with phenol red as indicator was used when a clear-cut acid reaction in the Kligler iron agar slant could not be determined.

An agar plate method was used to demonstrate DNase activity of microorganisms on deoxyribonucleic acid (DNA) (Jeffries, Holtman, and Guse, 1957). Strains were band streaked with an inoculating needle on DNase test medium (Baltimore Biological Laboratory) and were tested after a growth period of 18 to 24 hours at $37^{\circ} \mathrm{C}$. Hydrolytic activity was determined by adding a small amount of $1 \mathrm{~N} \mathrm{HCl}$ to the culture growth on the plate. A clear zone around the colony indicated DNase activity. A cloudy precipitate around the colony and throughout the plate resulted from the action of $\mathrm{HCl}$ on the salts of DNA in the medium and equalled a negative reaction. A DNase-positive Staphylococcus served as a positive control.

\section{RESULTS}

Biochemical reactions and DNase activity of these organisms are summarized in Table I. Results of the gelatin and DNase test distinguished Hafnia species from Serratia. Five of six E. cloacae strains produced clear-cut acid reactions in Kligler iron agar slants which, together with slower liquefaction of gelatin and negative DNase production, were used to differentiate these organisms from Serratia. The other cloacae culture utilized lactose in broth. The reaction in Kligler iron agar, liquefaction of gelatin after 24 hours, and negative DNase activity were used to separate E. liquefaciens from Serratia. It should be noted that some liquefaciens strains fail to form acid from lactose or do so late at $37^{\circ} \mathrm{C}$.

All of the Serratia strains tested yielded DNase activity even though the clearing of the zone was not quite as distinct as that produced by the positive Staphylococcus control. The size of the zones was consistently less than that of the positive control but sufficiently large (3-4 $\mathrm{mm}$ or greater in radius) in most instances to be easily recognized. Three of the strains on repeated study produced a light hazy zone around the colony but the zone extended at least $3 \mathrm{~mm}$ in diameter beyond the edge of the colony which was comparable to the results given by some of the other Serratia organisms. None of the Hafnia or Enterobacter species tested gave a positive DNase test by the qualitative agar plate method used.

\section{DISCUSSION}

Other workers have pointed out the fact that bacteria other than Staphylococci produce DNases and that most of the enteric bacteria except Serratia fail to do so (Eaves and Jeffries, 1963; Rothberg and Swartz, 1965; Valu, 1966). Only recently has attention been focused on the use of these enzymes as a means of identifying pathogenic bacteria. In order to elucidate the use of DNase as a major diagnostic tool in separating Serratia from other closely related enteric bacilli, 51 strains were studied. All of these produced DNase activity.

As standard bacteriological techniques were developed to distinguish more closely enterobacteria from each other, non-pigmented Serratia strains began to be recognized. Ewing and his associates found that three-fourths of over 200 strains they examined in 1959 failed to produce pigments (Ewing, Davis, and Reavis, 1959). In our laboratory we isolated 10 unpigmented strains of Serratia from clinical material over a six-month period in 1964 (Elston, 1965). Non-pigmented, non-lactose-fermenting organisms may be mistaken for Hafnia species or E. liquefaciens. Although E. liquefaciens (especially when lactose may not be fermented at $37^{\circ} \mathrm{C}$ ) is the most difficult of the two to differentiate from non-chromogenic Serratia biochemically, it is seldom encountered in diagnostic work. E. cloacae is less confusing since lactose fermentation can usually be determined in the Kligler iron agar slant. The gelatin and motility studies, which are a part of the routine screening tests used in this study, should be completed at room temperature and at $37^{\circ} \mathrm{C}$. If not, E. liquefaciens and Hafnia organisms may not be identified.

\section{TABLE I}

ROUTINE TESTS AND DEOXYRIBONUCLEASE ACTIVITY FOR DIFFERENTIATION OF SERRATIA AND CLOSELY RELATED ENTERIC BACILLI

\begin{tabular}{|c|c|c|c|c|c|c|c|c|c|}
\hline \multirow[b]{2}{*}{ Organism } & \multirow{2}{*}{$\begin{array}{l}\text { No. of } \\
\text { Strains }\end{array}$} & \multicolumn{2}{|c|}{ Acid Kligler Iron Agar } & \multirow[b]{2}{*}{ Urease } & \multirow[b]{2}{*}{ Indole } & \multirow[b]{2}{*}{ Citrate } & \multirow[b]{2}{*}{ Gelatin } & \multirow[b]{2}{*}{ Motility } & \multirow[b]{2}{*}{$\begin{array}{l}\text { DNase } \\
\text { Activity }\end{array}$} \\
\hline & & $\overline{B u t t}$ & Slant & & & & & & \\
\hline $\begin{array}{l}\text { Serratia } \\
\text { Hafnia } \\
\text { E. cloacae } \\
\text { E. liquefaciens }\end{array}$ & $\begin{array}{r}51 \\
33 \\
6 \\
3\end{array}$ & $\begin{array}{l}(51)+ \\
(33)+ \\
(6)+ \\
(3)+\end{array}$ & $\begin{array}{l}\overline{ } \\
(5)+ \\
(3)+\end{array}$ & $\begin{array}{l} \pm \\
\pm \\
\pm \\
\pm\end{array}$ & E & $\begin{array}{l}+ \\
+ \\
+ \\
+\end{array}$ & $\frac{+R}{+}$ & $\begin{array}{l}+ \\
\pm \\
+ \\
+\end{array}$ & $\frac{ \pm}{-}$ \\
\hline
\end{tabular}

$+=$ Reaction obtained $-=$ no reaction or negative test; $\pm=$ some strains positive, others negative.

$+\mathbf{R}=$ Rapid liquefaction (within 24 hours). 
Commonly, these organisms are identified by a battery of bacteriological tests. A lengthy series of tests delays reports and is not practical in a small laboratory. The addition of the DNase test to a select few biochemical tests as indicated here, is useful as a part of a screening procedure in distinguishing Serratia from closely related organisms. The use of this test might eliminate Serratia organisms from subsequent biochemical and serological investigations. Its helpfulness lies in its convenience, and in its ability to demonstrate hydrolytic activity after a short period of time ( 18 to 24 hours). It is believed that the DNase test is of distinct value as a routine aid in enteric bacteriology.
This work was performed with the excellent technical assistance of Mr. William A. Salisbury.

\section{REFERENCES}

Brown, A. L. (1950). J. Bact., 60, 673.

Cunningham, L. (1959). Ann. N. Y. Acad. Sci., 81, 788.

Eaves, G. N., and Jeffries, C. D. (1963). J. Bact., 85, 273.

Elston, H. R. (1965). J. clin. Path., 18, 618.

-, and Fitch, D. M. (1964). Amer. J. clin. Path., 42, 346.

Ewing, W. H., Davis, B. R., and Reavis, R. W. (1959). CDC Laboratory Manual, Communicable Disease Center, Atlanta, Georgia. Fusillo, M. H., and Weiss, D. L. (1959). J. Bact., 78, 520.

Jeffries, C. D., Holtman, D. F., and Guse, D. G. (1957). Ibid., 73, 590. Leham, I. R., and Richardson, C. C. (1964). J. biol. Chem., 239, 233. Potter, J. L., and Laskowski, M. (1959). Ibid., 234, 1263.

Rothberg, N. W., and Swartz, M. N. (1965). J. Bact., 90, 294.

Valu, J. A. (1966). Ibid., 91, 467.

Wannamaker, L. W. (1958). J. exp. Med., 107, 797.

Weckman, B. G., and Catlin, B. W. (1957). J. Bact., 73, 747.

\section{SCIENTIFIC REPORTS}

1 Colorimeters with Flow Through Cells. A critical assessment of 4 instruments. 1965 . P. M. G. BROUGHTON and C. RILEY. 13s. 6d.

2 Colorimeters. A critical assessment of 5 commercial instruments. 1966. P. M. G. BROUGHTON, C. RILEY, J. G. H. COOK, P. G. SANDERS and H. BRAUNSBERG. $15 \mathrm{~s}$.

3 Automatic Dispensing Pipettes. An assessment of 35 commercial instruments. 1967. P. M. G. BROUGHTON, A. H. GOWENLOCK, G. M. WIDDOWSON and K. A. AHLQUIST. 10s.

\section{TECHNICAL BULLETINS}

3 Non-recording Spectrophotometers for the Visible and Ultraviolet Ranges. A comparative table of instruments available in Great Britain. May 1965. A. H. GOWENLOCK, P. C. NICHOLAS and J. H. WILKINSON. 1s. 6 d.

5 Recording Spectrophotometers. A comparative list of low-priced instruments readily available in Britain. July 1965. P. SEWELL. 2s. 6d.
6 A Guide to Automatic Pipettes. A list of more than 100 instruments compiled from manufacturers' literature. August 1965. P. M. G. BROUGHTON. 5s.

7 Variability Between AutoAnalyzer Modules. August 1965. B. E. NORTHAM. 1s. 6 d.

8 Flame Photometers. A comparative list of 15 instruments readily available in Britain. June 1966. C. RILEY. $4 \mathrm{~s}$.

9 Determination of Urea by AutoAnalyzer. November 1966. RUTH M. HASLAM. 2s. 6d.

10 Filter Fluorimeters. A comparative list of 14 in- 을 struments. March 1967. HANNELORE BRAUNSBERG. 5s.

11 Determination of Serum Albumin by AutoAnalyzer using Bromocresol Green. October 1967 B. E. N NORTHAM and G. M. WIDDOWSON. 2s. 6 d.

12 Control Solutions for Clinical Biochemistry. February 1968. P. M. G. BROUGHTON 2s. 6d. 